\title{
REGRESSION MODELLING FOR PREDICTING VISIBILITY IN A TROPICAL URBAN ENVIRONMENT
}

\author{
SAVITHA ULAVI \& SARAGUR MADANAYAK SHIVA NAGENDRA \\ Department of Civil Engineering, Indian Institute of Technology, India
}

\begin{abstract}
Air pollution and visibility reduction is a major concern in cities. The present study focused on understanding the impact of air quality and meteorology on visibility impairment for a tropical coastal city (Chennai, India). Visibility measurements were carried out for 176 days representing summer, winter and post-monsoon season. The meteorological and air quality parameters for the study period were taken from the nearest continuous monitoring station supervised by the Central Pollution Control Board of India (located within $2 \mathrm{~km}$ of the visibility monitoring site). It was found that the average visibility experienced by the city is $11.24 \pm 5.47 \mathrm{~km}$. The seasonal variations in the data monitored showed maximum average visibility $(15.06 \pm 2.87 \mathrm{~km})$ during summer, followed by winter $(7.64 \pm$ $3.53)$ and post-monsoon season $(5.80 \pm 2.72)$. The stepwise linear regression model was developed to predict visibility. The model developed for winter showed $\mathrm{PM}_{2.5}$ is the significant predictor with reasonable $\mathrm{R}^{2}$ value of 0.68 . It was observed that there is a strong negative correlation between fine particulate matter $\left(\mathrm{PM}_{2.5}\right)$ and visibility. During summer ozone, $\mathrm{PM}_{2.5}$, wind speed, relative humidity, oxides of nitrogen $\left(\mathrm{NO}_{\mathrm{x}}\right)$ turned out to be the significant predictors for visibility and Pearson correlation showed inverse correlation between visibility and ozone (-0.683), as well as $\mathrm{PM}_{2.5}(-0.587)$. Thus the model developed for summer was able to capture the photochemistry of the summer and explained $71 \%$ variation in visibility. The number of low visibility events $(<2 \mathrm{~km})$ were estimated for different seasons excluding fog events $(\mathrm{RH}>90)$. The results showed large numbers of low visibility events in winter (348) followed by post-monsoon (205). The results also indicated that haze events increased with an increase in particulate matter concentration $\left(>60 \mu \mathrm{g} / \mathrm{m}^{3}\right), \mathrm{RH}(>65)$ and decrease in wind speeds $(<1 \mathrm{~m} / \mathrm{s})$.
\end{abstract}

Keywords: air pollution, regression, meteorology, visibility reduction.

\section{INTRODUCTION}

Poor air quality due to fine particulate matter (aerodynamic diameter $<2.5 \mu \mathrm{m}$ ) pollution and visibility reduction is a major concern in cities. The phenomenon of urban visibility reduction is complex and manifests as a result of interaction of air emissions and meteorology. The basic mechanism attributable to low visibility is scattering and absorption by gases and particles in the atmosphere [1], [2]. Meteorological parameters like wind speed, wind direction, ambient temperature, relative humidity influence visibility indirectly by influencing sources and sinks of gases and particulate matter [3]. There could exist a several combinations of meteorological parameters say low wind speed and high humidity which could lead to increased residence time of pollutants, there by higher pollutant build up leading to inversion/stable atmospheric conditions. This increased aerosol loading could further reduce solar radiation reaching earth's surface, leading to depressed planetary boundary layer which intern progress towards weakened diffusion [2], [4]. In addition particulate mass concentration, particle number concentration, size, chemical composition, mixing state and hygroscopicity have a significant impact on visibility impairment [5], [6].

Quantification of relationship between visibility, air quality and meteorology is critical for understanding physical or chemical processes which impair visibility and to forecast poor visibility events. Such studies on urban visual air quality as well play important role in shaping environmental policy and management response system. The present study focused on understanding the following aspects: (i) monitoring and characterizing of visibility for 
tropical coastal urban environment; (ii) to quantify a relation between visibility, air quality and meteorology through a stepwise linear regression model; and (iii) to explore the possible mechanism or underlying theory which may contribute for visibility reduction in different seasons and to analyse the low visibility events.

\section{STUDY AREA DESCRIPTION AND MEASUREMENTS}

The monitoring site is located in Chennai, a coastal city situated on Coromandel coast of the Bay of Bengal $\left(13.0827^{\circ} \mathrm{N}, 80.2707^{\circ} \mathrm{E}\right)$. It is a fast growing Indian metropolitan city with a population of 8.6 million [7]. Rapid urbanisation, industrial and vehicular growth has resulted in a greater environmental stress over city. The earlier studies carried out which aimed at understanding the prevailing air quality in a city (between 1991 to 2005) have shown exceedance of $\mathrm{PM}_{10}, \mathrm{NO}_{x}$, surface ozone concentrations at several pockets of Chennai [8], [9]. In addition the source apportionment studies carried out post 2005 in Chennai have reported presence of increased particulate phase sulphate, gaseous phase oxides of nitrogen and EC/OC ratio in particulate matter [10]. This type of atmospheric composition indicate potential for increased particulate hygroscopicity, enhanced light absorption and scattering there by posing greater risk of atmospheric visibility deterioration.

With orientation to climate of city, Chennai is hot and humid throughout the year. It experiences summer (March-May), winter (January and February). The monsoon period is classified as pre-monsoon (south-west monsoon) June to September and post-monsoon (north-eastern monsoon) from October to December [11]. Chennai experiences tropical wet and dry climate as per Koppen climate classification. Visibility monitoring was carried out on a roof top (20 meters above ground level) of Indian Institute of Technology Madras (IITM) Engineering Design building block (shown in Fig. 1). IITM campus is a beautiful wooded land spread over 250 acres and the campus is surrounded by residential area, educational and research institutes and commercial centres thereby heavy traffic roads. Thus the monitoring site serves as a perfect urban background. Belfort model 6000 visibility sensor was used to monitor visibility and it works on the principles of forward light scattering (used in earlier studies [12], [13]). Visibility range the instrument can detect is $6 \mathrm{~m}$ to $80 \mathrm{~km}$ with accuracy of $\pm 10 \%$. Visibility data was captured for every minute and monitoring was carried out for 61 days representing summer (April and May 2018), 56 days representing post-monsoon (November and December 2018) and 59 days representing winter (January and February 2019). Meteorological (relative humidity, wind speed, wind direction) and air quality parameters $\left(\mathrm{PM}_{2.5}, \mathrm{SO}_{2}, \mathrm{NO}_{\mathrm{x}}\right.$, ozone) were taken from $\mathrm{CPCB}$ continuous monitoring site located within IITM campus [14].

\subsection{Methods}

The data collected from CPCB was examined for outliers using Quartile method. Every one minute average visibility data, monitored and every 15 minute average air quality and meteorological data, obtained from CPCB was converted into daily average values. IBM SPSS statistics Version 25 was used to build season-wise regression model and to carry out statistical analysis. Origin Pro 2015 was used as plotting software. MatLab version R2015a was used as a coding platform to find planetary boundary height from radiosonde observations. The data points corresponding to $\mathrm{RH}>90$ were eliminated (as to exclude fog events contributing for low visibility) and haze events were examined. 

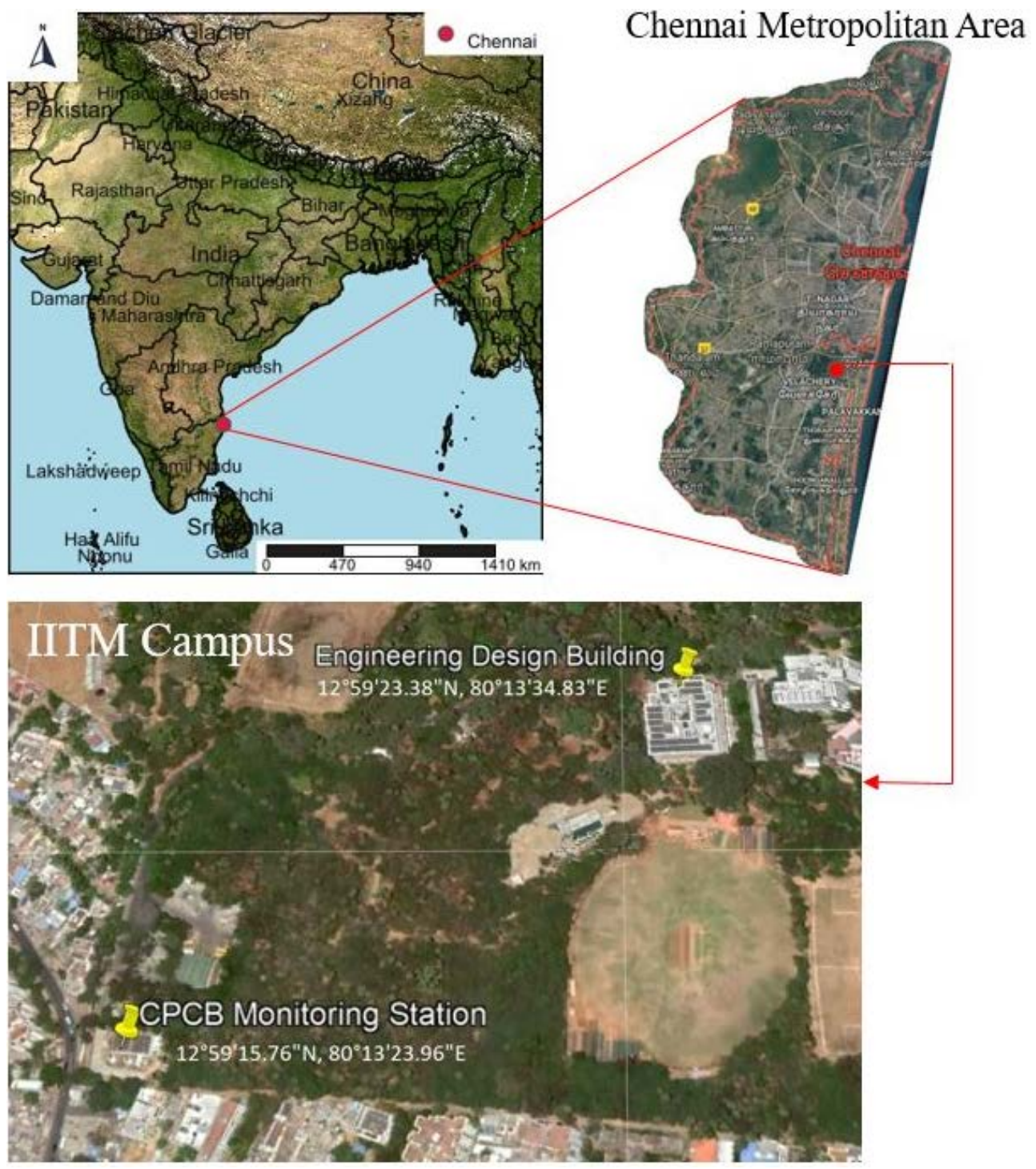

Figure 1: Satellite view of India highlighting the geographical location of monitoring site in Chennai.

\section{RESULTS AND DISCUSSION}

\subsection{Characteristics of visibility monitored and seasonal variations}

The average visibility experienced by the city is $11.24 \pm 5.47 \mathrm{~km}$ with a modal value being $14 \mathrm{~km}$ (for 176 days representing summer, post-monsoon and winter season). The average extinction coefficient is $0.40 \mathrm{~km}^{-1}$ (at $880 \mathrm{~nm}$ ). The five number summary (refers to descriptive measures in statistics) minimum $<\mathrm{Q}_{1}<$ median $<\mathrm{Q}_{3}<$ maximum is estimated to be 
$2.44<5.17<8.96<13.67<21.70$. The five number summary was calculated considering the daily average and it is clear that $50 \%$ of the data set is below $8.96 \mathrm{~km}$ (indicative of haze). The test for normality using normal Q-Q plot and Kolmogorov-Smirnov test showed data is normally distributed $(\mathrm{N}=30847)$ with a significance value of 0.0 . The seasonal variations in data have been observed (shown in Fig. 2). Summer marks the better visibility with a mean value of $15.60 \pm 4.16 \mathrm{~km}$. However during both post-monsoon and winter season visibility is below $10 \mathrm{~km}$ indicating the occurrence of hazy days. The impaired visibility days were characterized by increased $\mathrm{PM}_{2.5}$ concentration shown in time series plot of visibility, air quality and meteorological parameters in Fig. 3. The lag effect was observed between $\mathrm{NO}_{\mathrm{x}}$ and $\mathrm{PM}_{2.5}$ (increase in oxides of nitrogen concentration is followed by sharp rise in fine particulate concentration). This could be possibly due to heterogeneous gas to particle conversion reactions. $57 \%$ of the daily average during the monitoring period showed visibility less than $10 \mathrm{~km}$.

\subsection{Quantifying relation between visibility, air quality and meteorology}

The step wise linear regression was performed to quantify the relation between air quality, meteorology and visibility. The results of regression model developed showed a reasonable $\mathrm{R}^{2}$ value of 0.502 and fine particulate matter, wind speed and ozone were found to be the significant predictors (given in eqn (1))

$$
\text { Visibility }=12.091-0.111\left(\mathrm{PM}_{2.5}\right)+0.8817(\mathrm{WS})-0.73 \text { (ozone) }
$$

A further attempt was made to know if there is any improvement in the model by considering the seasonal data. Thus steps were repeated and model was rebuilt for winter, summer and post-monsoon season.

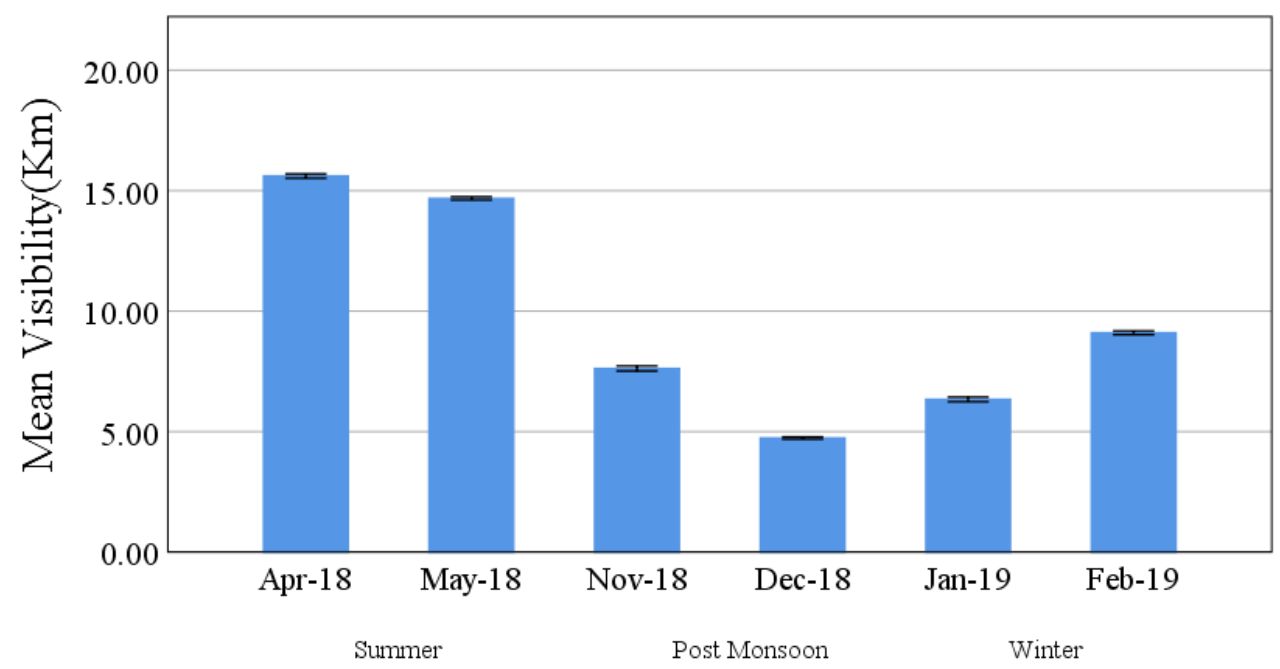

Error Bars: $95 \%$ CI

Figure 2: Seasonal variations in visibility experienced by Chennai. 


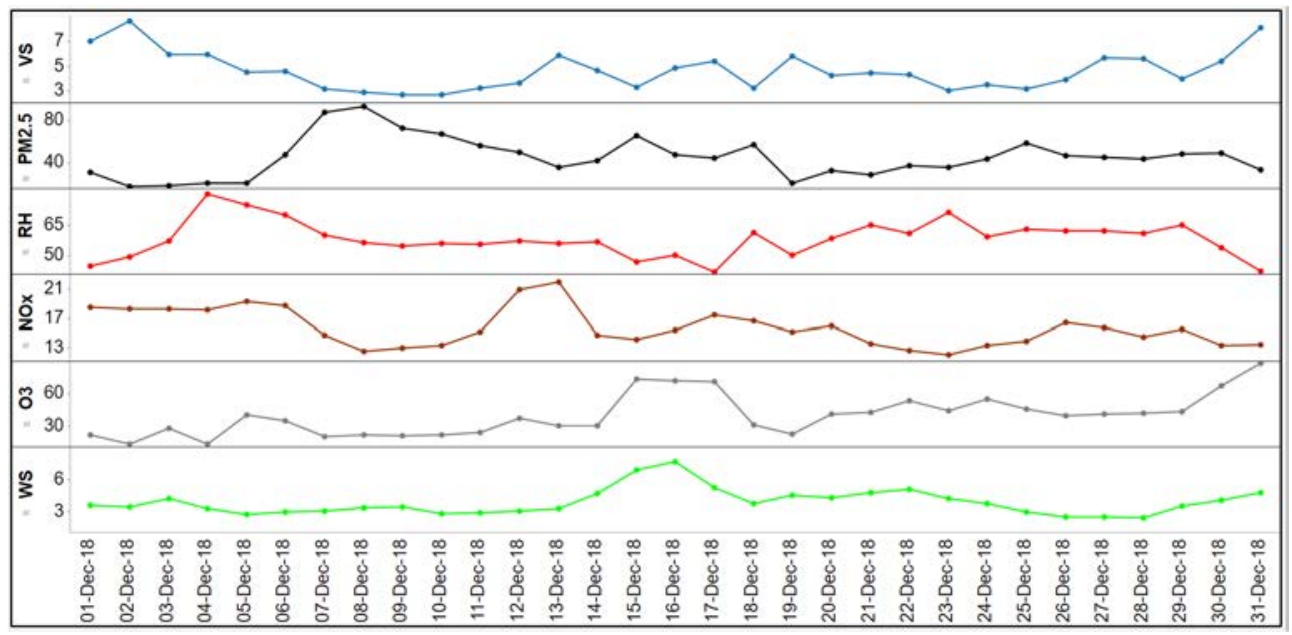

Figure 3: Time series plot showing variations in visibility ( $\mathrm{VS}=$ blue), particulate matter $\left(\mathrm{PM}_{2.5}=\right.$ black $)$, relative humidity $(\mathrm{RH}=$ red $)$, oxides of nitrogen $\left(\mathrm{NO}_{\mathrm{X}}=\right.$ brown $)$, ozone $\left(\mathrm{O}_{3}=\right.$ grey $)$ and wind speed $(\mathrm{WS}=$ green $)$ for December 2018 .

\subsubsection{Winter}

It was interesting to know that $\mathrm{PM}_{2.5}$ turned out to be the significant predictor variable during winter and $68.2 \%$ of variations in visibility could be explained by fine particulate matter alone $\left(\mathrm{R}^{2}=0.682\right)$ given in eqn $(2)$. The Pearson correlation study showed there exits strong negative or inverse correlation between visibility and $\mathrm{PM}_{2.5}(-0.826)$ and ozone $(-0.52)$. Positive correlation was observed between visibility and wind speed (shown in Table 1). Stepwise regression equation obtained for winter is presented in eqn (2)

$$
\text { Visibility }=14.304-0.202\left(\mathrm{PM}_{2.5}\right) \text {. }
$$

Table 1: Pearson correlation between visibility, air quality and meteorological parameters.

\begin{tabular}{|l|c|c|c|c|c|c|}
\hline Parameters & Visibility & $\mathrm{PM}_{2.5}$ & $\mathrm{NO}_{\mathrm{x}}$ & Ozone & $\mathrm{RH}$ & WS \\
\hline Visibility & 1.00 & -0.826 & -0.256 & -0.52 & -0.078 & 0.329 \\
\hline $\mathrm{PM}_{2.5}$ & & 1.00 & 0.429 & 0.475 & -0.003 & -0.330 \\
\hline $\mathrm{NO}_{\mathrm{x}}$ & & & 1.00 & -0.125 & -0.122 & 0.170 \\
\hline Ozone & & & & 1.00 & -0.326 & -0.319 \\
\hline $\mathrm{RH}$ & & & & & 1.00 & -0.68 \\
\hline WS & & & & & & 1.00 \\
\hline
\end{tabular}

This could be possibly due to radiation inversion conditions, suppressed planetary boundary layer which generally prevail during winter season. These stable weather conditions trap the pollutants close to the earth's surface and affect optical properties of the atmosphere (scattering and absorption) there by reducing the ambient visibility. The distribution fit between visibility and $\mathrm{PM}_{2.5}$ showed exponential decay relation during winter (with $\mathrm{R}^{2} 0.80$ ). 


\subsubsection{Summer}

In summer ozone, $\mathrm{PM}_{2.5}$, WS, $\mathrm{RH}, \mathrm{NO}_{\mathrm{x}}$ turned out to be the significant predictors for visibility with $\mathrm{R}^{2}$ value of 0.709 . Pearson correlation showed strong negative correlation between visibility and ozone (-0.683), $\mathrm{PM}_{2.5}(-0.587)$. Stepwise regression model summary for summer is given in Table 2 and the regression equation in eqn (3). Fig. 4 depicts frequency histogram for standardized residual and normal P-P plot.

Visibility = 32.23-0.126(ozone)-0.057( $\left.\mathrm{PM}_{2.5}\right)-0.199(\mathrm{WS})-0.14(\mathrm{RH})-0.037\left(\mathrm{NO}_{\mathrm{x}}\right)$.

Table 2: Model summary for stepwise linear regression - summer data.

\begin{tabular}{|cc|c|c|c|c|}
\hline \multirow{2}{*}{ Model } & \multirow{2}{*}{$\mathrm{R}$} & R square & Adjusted R square & $\begin{array}{c}\text { Standard error } \\
\text { of the estimate }\end{array}$ & Durbin-Watson \\
\hline 1 & $0.683^{\mathrm{a}}$ & 0.467 & 0.458 & 2.11612 & \\
\hline 2 & $0.769^{\mathrm{b}}$ & 0.592 & 0.577 & 1.86806 & \\
\hline 3 & $0.806^{\mathrm{c}}$ & 0.650 & 0.632 & 1.74376 & \\
\hline 4 & $0.825^{\mathrm{d}}$ & 0.680 & 0.657 & 1.68247 & \\
\hline 5 & $0.842^{\mathrm{e}}$ & 0.709 & 0.682 & 1.61946 & 1.102 \\
\hline
\end{tabular}

a. Predictors: (Constant), Ozone

b. Predictors: (Constant), Ozone, $\mathrm{PM}_{2.5}$

c. Predictors: (Constant), Ozone, $\mathrm{PM}_{2.5}$, WS

d. Predictors: (Constant), Ozone, $\mathrm{PM}_{2.5}$, WS, RH

e. Predictors: (Constant), Ozone, $\mathrm{PM}_{2.5}$, WS, RH, $\mathrm{NO}_{\mathrm{x}}$

f. Dependent variable: Visibility
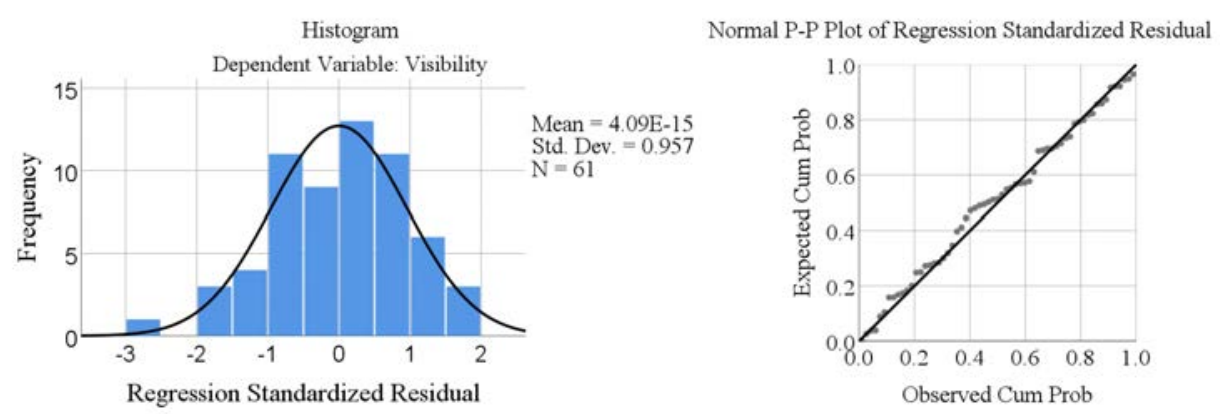

Figure 4: Frequency histogram for standardized residual and normal P-P plot.

Ground level ozone and secondary particulates formation through complex photochemical reactions during peak summer hours has been studied and reported in multiple urban environments [15], [16]. The presence $\mathrm{O}_{3}$ and several other radicals (like Hydroxyl radical$\mathrm{OH}$, Peroxy radicals- $\mathrm{RO}_{2}$ etc.) increase the oxidizing capacity of the atmosphere which intern increase the secondary fine aerosol particle $(0.1 \mu \mathrm{m}$ to $1 \mu \mathrm{m})$ by gas to particle conversion process. This secondary fine particulate matter formed ultimately lead to visibility reduction 
[17], [18]. Thus the model developed for summer (eqn (3)) is able to capture the photochemistry of summer (smog) and explains approximately $71 \%$ of variation in visibility.

\subsubsection{Post-monsoon}

During post-monsoon season $\mathrm{PM}_{2.5}$, ozone (-0.414 and -0.321 respectively) showed negative correlation with visibility and RH showed no significant correlation with visibility. The variation in visibility explained by the model (eqn (4)) was found to be low (29.1\%).

$$
\text { Visibility }=14.18-0.061\left(\mathrm{PM}_{2.5}\right)-0.051(\text { ozone })-0.069(\mathrm{RH}) \text {. }
$$

Post-monsoon season is the period where Chennai city receives major portion of its rainfall. The low $\mathrm{R}^{2}$ value could be possibly due to unaccounted factors in the model like washout or precipitation events, seasonal changes in wind pattern, cloud cover, etc.

During this season the lowest visibility value observed was $2.65 \mathrm{~km}$ and corresponding $\mathrm{PM}_{2.5}$ concentration was $73 \mu \mathrm{g} / \mathrm{m}^{3}$ (on 9/12/2018) and the highest visibility value witnessed was $14 \mathrm{~km}$ (on 6/11/2018) with corresponding $\mathrm{PM}_{2.5}$ concentration of $39 \mu \mathrm{g} / \mathrm{m}^{3}$. However there were 12 days with $\mathrm{PM}_{2.5}$ concentration lower than $30 \mu \mathrm{g} / \mathrm{m}^{3}$ which did not witness better visibility. The reduction in fine particulate matter due to wet deposition as a result of drizzle or precipitation events. However though particle concentration was reduced, precipitation events would have simultaneously increased the local relative humidity leading to increased extinction of light and there by visibility reduction [19].

\subsection{Examination of low visibility occurrences}

During visibility monitoring period severe low visibility $(<2 \mathrm{~km})$ events were observed. Most often low visibility episodes occur due to fog, haze and fog-haze mixed events. However in the present study RH $>90$ were not considered, thus fog events contributing to visibility impairment are excluded. Haze has been often reported as weather phenomena where visibility $<10 \mathrm{~km}$ at $\mathrm{RH}$ below $90 \%$ [19] and haze episodes are characterized by excessive aerosol loading. The occurrence of severe low visibility events were highest during winter (348) followed by post-monsoon season (205). As depicted in Fig. 5, the possibility of haze events increase with increase in $\mathrm{RH}$ and particulate matter concentration and decrease in wind speed. Most of these events have occurred during early morning and mid night hours. The reason for such events during night and early morning hours would be the formation of stable-nocturnal boundary layer. Thus to justify this planetary boundary layer (PBL) data for Chennai city was analysed from radiosonde observations [20]. The data is available for morning $(5: 30 \mathrm{am})$ and evening $(5: 30 \mathrm{pm})$. The Pearson correlation performed between visibility and PBL for dataset showed positive correlation during January (0.578), February (0.210) during winter. This means that as the PBL increases visibility increases and vice versa, however for post-monsoon season no significant correlations were observed. PBL varied between $0.6-2 \mathrm{~km}$ during low visibility events.

The national ambient air quality standard for $\mathrm{PM}_{2.5}$ is $60 \mu \mathrm{g} / \mathrm{m}^{3}$ (24 hour average). It is clear from the Fig. 5 that large number of haze episodes have occurred even when the $\mathrm{PM}_{2.5}$ concentrations are below the standard, when RH exceeds 70 and wind speeds are lower than $0.5 \mathrm{~m} / \mathrm{s}$ during winter. However no severe low visibility events were observed during summer though $\mathrm{RH}>70$ at several instances. The lowest visibility recorded during summer is $4.35 \mathrm{~km}$. This could be possibly due to decrease in the strength of land sea breeze effect during post-monsoon and winter periods (as sea-breeze circulation occurs when $5^{\circ} \mathrm{C}$ or 

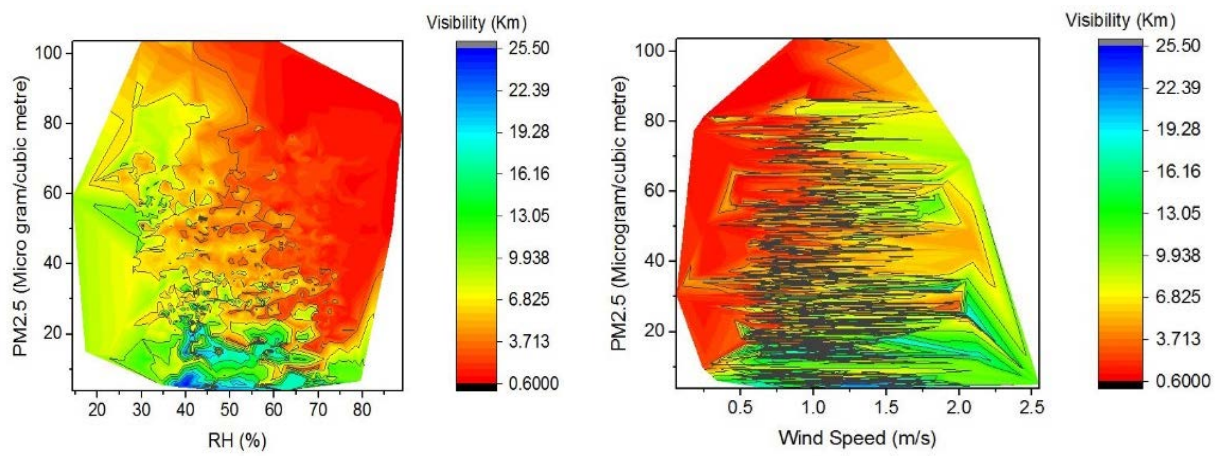

Figure 5: Occurrence of low visibility events during winter period (January 2019) and relation with $\mathrm{PM}_{2.5}$, relative humidity and wind speed.

greater temperature difference between land and water body [21]. The lower wind speeds favour accumulation of moisture in the ambient environment, which further favours hygroscopic growth of particles leading to excessive extinction of light. Thus it clearly indicates that there is need for season specific ambient air quality standards to be practiced or more stringent $\mathrm{PM}_{2.5}$ emission reduction norms during winter for experiencing better visibility.

\section{CONCLUSION}

Visibility monitoring campaign was carried out for 176 days representing summer, winter and post-monsoon season. From the results obtained it is found that Chennai city experiences average visibility of $11.24 \pm 5.47 \mathrm{~km}$ with modal value of $14 \mathrm{~km}$. Further analysis of seasonal variations in visibility infer, visibility is better in summer $(15.60 \mathrm{~km})$ followed by winter $(7.64 \mathrm{~km})$ and post-monsoon season $(5.80 \mathrm{~km})$. City experiences hazy days $(<10 \mathrm{~km})$ during winter and post-monsoon season. Stepwise linear regression for winter showed fine particulate matter $\left(\mathrm{PM}_{2.5}\right)$ is the significant predictor explaining $68 \%$ variation in visibility. However for summer it is observed that ozone, $\mathrm{PM}_{2.5}, \mathrm{WS}, \mathrm{RH}, \mathrm{NO}_{\mathrm{x}}$ are the significant predictors, which together explain $71 \%$ variation in visibility and indicated that model captures the photochemistry of the summer. The occurrence of low visibility events are found to be highest during winter followed by post-monsoon season and positive correlation was observed between PBL and visibility during winter.

\section{REFERENCES}

[1] Zhao, H. et al., Characteristics of visibility and particulate matter in an urban area of northeast China. Atmospheric Pollution Research, 4(4), pp. 427-434, 2013. DOI: 10.5094/APR.2013.049.

[2] Quan, J., Tie, X., Zhang, Q., Liu, Q., Li, X. \& Gao, Y., Characteristics of heavy aerosol pollution during the 2012-2013 winter in Beijing, China. Atmospheric Environment, 88, pp. 83-89, 2014. DOI: 10.1016/j.atmosenv.2014.01.058.

[3] Singh, A., Bloss, W.J. \& Pope, F.D., 60 years of UK visibility measurements: Impact of meteorology and atmospheric pollutants on visibility. Atmospheric Chemistry and Physics, 17(3), pp. 2085-2101, 2017. DOI: 10.5194/acp-17-2085-2017.

[4] Luan, T., Guo, X., Guo, L. \& Zhang, T., Quantifying the relationship between $\mathrm{PM}_{2.5}$ concentration, visibility and planetary boundary layer height for long-lasting haze and 
fog-haze mixed events in Beijing. Atmospheric Chemistry and Physics, pp. 203-225, 2018. DOI: 10.5194/acp-18-203-2018.

[5] Titos, G., Cazorla, A., Zieger, P., Andrews, E. \& Lyamani, H., Effect of hygroscopic growth on the aerosol light-scattering coefficient: A review of measurements, techniques and error sources. Atmospheric Environment, 141, pp. 494-507, 2016. DOI: 10.1016/j.atmosenv.2016.07.021.

[6] Seinfield, J.H. \& Pandis, S.N., Atmospheric Chemistry and Physics: From Air Pollution to Climate Change, 3rd ed., John Wiley \& Sons, 2016.

[7] Population Census 2011. www.census2011.co.in/.

[8] Gupta, I. \& Kumar, R., Trends of particulate matter in four cities in India. Atmospheric Environment, 40, pp. 2552-2566, 2006.

[9] Pulikesi, M., Baskaralingam, P., Elango, D., Rayudu, V.N., Ramamurthi, V. \& Sivanesan, S., Air quality monitoring in Chennai, India in the summer of 2005. Journal of Hazardous Materials, B136, pp. 589-596, 2006.

[10] CPCB, Report on air quality monitoring, emission inventory and source apportionment study for Chennai. http://cpcb.nic.in/displaypdf.php?id=Q2hlbm5haS5wZGY.

[11] Attri, S.D. \& Tyagi, A., Climate Profile of India: Indian Meteorological Department (IMD), Ministry of Earth Sciences, 1-5, 2010.

www.indiaenvironmentportal.org.in/files/climate_profile.pdf.

[12] Cheng, Z. et al., Long-term trend of haze pollution and impact of particulate matter in the Yangtze River Delta, China. Environmental Pollution, 182, pp. 101-110, 2013. DOI: 10.1016/j.envpol.2013.06.043.

[13] Yang, Y.R. et al., Characteristics and formation mechanism of continuous hazes in China: A case study during the autumn of 2014 in the North China Plain, pp. 81658178, 2015. DOI: 10.5194/acp-15-8165-2015.

[14] CPCB, Continuous monitoring station data. https:/app.cpcbccr.com/ccr/\#/caaqmdashboard-all/caaqm-landing.

[15] Ji, D. et al., Investigating the evolution of summertime secondary atmospheric pollutants in urban Beijing. Science of Total Environment, 572, pp. 289-300, 2016. DOI: 10.1016/j.scitotenv.2016.07.153.

[16] Kim, H., Zhang, Q. \& Heo, J., Influence of intense secondary aerosol formation and long-range transport on aerosol chemistry and properties in the Seoul metropolitan area during spring time: Results from KORUS-AQ. Atmospheric Chemistry and Physics, pp. 7149-7168, 2018. DOI: 10.5194/acp-18-7149-2018.

[17] Aneja, V.P., Brittig, J.S., Kim, D. \& Carolina, N., Ozone and other air quality-related variables affecting visibility in the southeast United States. Journal of Air and Waste Management Association, 54, pp. 681-688, 2004.

[18] Fabian, P. \& Dameris, M., Ozone in the Atmosphere: Basic Principles, Natural and Human Impacts, Springer Heidelberg: New York, 2014.

[19] $\mathrm{Fu}, \mathrm{X}$. et al., Changes in visibility with $\mathrm{PM}_{2.5}$ composition and relative humidity at a background site in the Pearl River Delta region. Journal of Environmental Science, 40, pp. 10-19, 2015. DOI: 10.1016/j.jes.2015.12.001.

[20] University of Wyoming, Atmospheric soundings. http://weather.uwyo.edu/upperair/ sounding.html.

[21] Stull, R.B., An Introduction to Boundary Layer Meteorology, Kluwer Academic Publishers, pp. 3-20, 1999. 